\title{
Excess Dielectric and Thermodynamical Studies on Hydrogen Bonded Binary Mixtures of Propan-1-ol with Methyl and Ethyl Benzoates
}

\author{
S. V. KUMARA SASTRY, S SREEHARI SASTRY and V R K MURTHY* \\ Department of Physics, Acharya Nagarjuna University, Nagarjunanagar-522510, India \\ *Department of Physics, Indian Institute of Technology, Chennai-600036, India \\ svkumarasastry@gmail.com
}

Received 1 June 2012 / Accepted 25 June 2012

\begin{abstract}
The molecular interactions between the polar systems propan-1-ol with alkyl benzoates (methyl benzoate and ethyl benzoate) for various mole fractions at different temperatures were studied by determining the dielectric permittivity using - LF impedance analyzer, microwave bench and Abbe's refractometer in radio, microwave and optic frequency regions respectively. Dipole moment, excess dipole moment, excess Helmholtz free energy, excess permittivity, relaxation time, excess inverse relaxation time and excess thermodynamical values are calculated using experimental data. Hamiltonian quantum mechanical calculations are performed on both pure and equimolar binary systems of propan-1-ol with alkyl benzoates for the measurement of dipole moment using PC Spartan and Argus lab Modeling softwares and these theoretical values are in good agreement with the experimental values. These studies can give information on its structure and interaction.
\end{abstract}

Keywords: Dipole moment, Excess Helmholtz frees energy, Relaxation time, Hamiltonian calculations

\section{Introduction}

Dielectric studies on mixtures of polar liquids either in pure state or in inert solvents have been a subject of interest because they provide useful information regarding the molecular complex formation in solution ${ }^{1}$. Molecular mixtures bring about changes in thermodynamic properties like entropy, free energy and also in physical properties like density, molar volume, refractive index, dielectric permittivity etc. ${ }^{2}$. Many studies on the fluid structures of polar and non-polar mixtures have been reported ${ }^{3,4}$. There is an increased interest in the study of liquid mixtures leading to formation of hydrogen bonding in the system due to solute-solvent interactions during the recent times ${ }^{5}$. Hydrogen bonding is complex in liquid state because of the uncertainty in identifying the particular bonds and the number of molecules involved. The presence of hydrogen bond brings a considerable change in the dielectric properties of liquid mixtures ${ }^{6}$. 
Alcohols are industrially and scientifically important organic compounds and their physical and chemical properties are largely determined by the $-\mathrm{OH}$ group. Alcohols are strongly associated in solution because of dipole-dipole interaction and hydrogen bonding. Aromatic ester solvents are a remarkable family of fluids with technological applications in very different fields ${ }^{7}$. The detailed knowledge of the molecular level structure of these fluids is required not only to improve the processes in which they are involved but also because of the theoretical importance of these compounds. Aromatic ester packings are disrupted upon mixing although very different effects arise depending on the nature of the second compounds of the mixture ${ }^{8-10}$. In order to get a deeper insight into the liquid structure of this mixture of fluids, we report here the values of dielectric data at different frequency regions; according to these experimental results, a better knowledge on their structure and dynamics can be gained. The nature of interaction between $\mathrm{CH}$ and $-\mathrm{OH}$ groups plays an important role in biological systems and drug synthesis ${ }^{9,11}$.

The present work aims at studying the dielectric behavior of pure and binary mixtures of propan-1-ol with methyl benzoate (System 1) and propan-1-ol with ethyl benzoate (System 2) in different frequency ranges for various mole fractions at different temperatures. From the experimental data, the dielectric parameters dipole moment, excess dipole moment, excess helmholtz free energy, excess permittivity, relaxation time, excess inverse relaxation time and excess thermodynamical values are calculated for the pure and binary mixtures ${ }^{12-16}$. Hamiltonian quantum mechanical calculations ${ }^{8}$ such as semi-empirical and $a b$ initio calculations are performed by optimized converged geometry operation using PC Spartan and Argus lab modeling softwares ${ }^{17,18}$. The obtained theoretical values are further compared with the experimental values.

\section{Experimental}

The compounds propan-1-ol (1PN), methyl benzoate (MB), ethyl benzoate (EB) and benzene of AR grade are procured from E. Merck, Germany and were purified by standard methods. The binary mixtures were prepared for different mole fractions i.e., mole fraction $\left(\mathrm{x}_{2}\right)$ of benzoates is varied from 0 to 1 in propan-1-ol (with a step increment of 0.1$)$. The temperature, $\mathrm{T}=(303$ to 323) K, controller system with a water bath, supplied by M/s Sakti Scientific Instruments Company-India, were used to maintain the constant temperature with an uncertainty $\pm 1 \mathrm{~K}$. The mass measurements were performed on a digital electronic balance (Mettler Toledo AB 135, Switzerland) with an uncertainty of $\pm 0.00001 \mathrm{~g}$. The Densities of the pure liquids were measured at corresponding temperatures by using a $10 \mathrm{~mL}$ specific gravity bottle.

The permittivity values at the spot frequencies $1 \mathrm{kHz}\left(\varepsilon_{\text {static }}\right), 10 \mathrm{kHz}, 100 \mathrm{kHz}, 1 \mathrm{MHz}$ and $10 \mathrm{MHz}$ for the above systems were measured using a HP-LF impedance analyzer (Model No: 4192 A) at different temperatures. The real ( $\left.\varepsilon^{\prime}\right)$ and imaginary ( $\left.\varepsilon^{\prime \prime}\right)$ parts of the complex dielectric permittivity $\left(\varepsilon^{*}=\varepsilon^{\prime}-j \varepsilon\right.$ ") were determined with Microwave bench (XBand, $8.60 \mathrm{GHz}$ ) using the Plunger technique ${ }^{19}$ at different temperatures. The high frequency dielectric permittivity $\left(\varepsilon_{\infty}=n^{2}\right)$ is obtained from the refractometer measurements using M/s ASCO make Abbe's refractometer with sodium D light as source at different temperatures .The average uncertainty in the measurement of $\varepsilon_{\text {static }}, \varepsilon^{\prime}, \varepsilon_{\infty}$ and density is 0.0002 and the average uncertainty in the measurement of $\varepsilon ", \tau$ is 0.002 . Dipole moments of the liquids in gaseous state are taken from literature ${ }^{20}$.

\section{Theory}

The dipole moments for the pure and equi molar systems (System 1 and 2) were measured experimentally, by diluting them in non-polar solvent benzene, using Higasi's method ${ }^{12}$. 


$$
\mu^{2}=\frac{27 \mathrm{kTM}_{2}\left(\mathrm{a}_{0}-\mathrm{a}_{\infty}\right)}{4 \pi \mathrm{Nd}_{1}\left(\varepsilon_{1}+2\right)^{2}}
$$

Where $M_{2}$ is molecular weight of solute, $d_{1}$ is density of solvent, $\varepsilon_{1}$ is the static dielectric permittivity of solvent (Benzene), $\mathrm{a}_{0}$ and $\mathrm{a}_{\infty}$ are the slopes of $\varepsilon_{\text {static }}$ and $\varepsilon_{\infty}$ with respect to the weight fraction of the solute respectively. The excess dipole moments $(\Delta \mu)$ of the systems are determined by the following equation ${ }^{13}$.

$$
\Delta \mu=\mu_{12}-\mu_{1}-\mu_{2}
$$

Where the dipole moment of $1 \mathrm{PN}$ is $\mu_{1}, \mu_{2}$ is the dipole moment of either MB or EB and $\mu_{12}$ is the dipole moment of the equi molar solute mixtures $1 \mathrm{PN}+\mathrm{MB}$ or $1 \mathrm{PN}+\mathrm{EB}$. The dipole moment increment is considered as a quantitative indication of the polarity of the hydrogen bond.

The excess Helmholtz free energy $\left(\Delta \mathrm{F}^{\mathrm{E}}\right)$ is a good dielectric parameter to evaluate the interaction between the components in the mixture through breaking mechanism of hydrogen bond and is expressed ${ }^{21}$ as

$$
\Delta \mathrm{F}^{\mathrm{E}}=\Delta \mathrm{F}_{o r}^{\mathrm{E}}+\Delta \mathrm{F}_{r r}^{\mathrm{E}}+\Delta \mathrm{F}_{12}^{\mathrm{E}}
$$

Where $\Delta \mathrm{F}_{o r}{ }^{\mathrm{E}}$ represents the excess dipolar energy due to long range electrostatic interaction, $\Delta \mathrm{F}_{r r}{ }^{\mathrm{E}}$ represents the excess dipolar energy due to the short range interaction between identical molecules and $\Delta \mathrm{F}_{12}{ }^{\mathrm{E}}$ represents the excess free energy due to short-range interaction between dissimilar molecules. The above terms are given in detail in equation (4)

$$
\begin{aligned}
\Delta \mathrm{F}^{\mathrm{E}}= & \frac{-\mathrm{N}_{\mathrm{A}}}{2}\left\{\sum_{\mathrm{r}=1,2} x_{\mathrm{r}}^{2} \mu_{\mathrm{r}}^{2}\left[\mathrm{R}_{\mathrm{fr}}-\mathrm{R}_{\mathrm{fr}}^{0}\right]+\sum_{\mathrm{r}=1,2} x_{\mathrm{r}}^{2} \mu_{\mathrm{r}}^{2}\left[\mathrm{~g}_{\mathrm{rr}}-1\right]\left[\mathrm{R}_{\mathrm{fr}}-\mathrm{R}_{\mathrm{fr}}^{0}\right]\right. \\
& \left.+x_{1} x_{2} \mu_{1} \mu_{2}\left[\mathrm{R}_{\mathrm{f}_{1}}+\mathrm{R}_{\mathrm{f}_{2}}-\mathrm{R}_{\mathrm{f}_{1}}^{0}-\mathrm{R}_{\mathrm{f}_{2}}^{0}\right]\right\}
\end{aligned}
$$

Where, $\mathrm{R}_{f r}^{0}=\left(\frac{8 \pi \mathrm{N}_{\mathrm{A}}}{9 \mathrm{~V}_{\mathrm{r}}}\right) \frac{\left(\varepsilon_{\mathrm{r}}-1\right)\left(\varepsilon_{\infty \mathrm{r}}+2\right)}{\left(2 \varepsilon_{\mathrm{r}}+\varepsilon_{\infty \mathrm{r}}\right)}, \mathrm{R}_{f r}=\left(\frac{8 \pi \mathrm{N}_{\mathrm{A}}}{9 \mathrm{~V}_{\mathrm{r}}}\right) \frac{\left(\varepsilon_{m}-1\right)\left(\varepsilon_{\infty \mathrm{r}}+2\right)}{\left(2 \varepsilon_{m}+\varepsilon_{\infty \mathrm{r}}\right)}, g_{12}=g_{\mathrm{f}}$,

$\mathrm{V}_{\mathrm{r}}$ is the molar volume of the components and $\varepsilon_{\mathrm{r}}, \varepsilon_{\infty \mathrm{r}}, \varepsilon_{\infty r}$ are the dielectric permittivity values at static and optic frequencies of the pure liquids respectively. The contribution of hydrogen bonds to the dielectric properties of the mixtures can be studied in terms of excess permittivity $\left(\varepsilon^{\mathrm{E}}\right)$. The excess permittivity, $\varepsilon^{\mathrm{E}}$, which provides qualitative information about formation of multimers in the mixture, can be computed ${ }^{22,23}$ as,

$$
\varepsilon^{E}=\left(\varepsilon_{m}-\varepsilon_{\infty \mathrm{m}}\right)-\left[\left(\varepsilon_{1}-\varepsilon_{\infty \mathrm{m}}\right) x_{1}+\left(\varepsilon_{2}-\varepsilon_{\infty \mathrm{m}}\right) x_{2}\right]
$$

Where $x$ mole fraction and suffix 1,2 and $\mathrm{m}$ is represents liquid 1, liquid 2 and mixture respectively. The qualitative information provided by excess permittivity about the mixtures is as follows. $\varepsilon^{E}=0$ indicates that there is no interaction between the components in the mixture.

$\varepsilon^{\mathrm{E}}<0$ indicates that the components in the mixture interact in such a way that the effective dipolar polarization gets reduced and the components may form multimers leading to less effective dipoles. $\varepsilon^{\mathrm{E}}>0$ indicates that the components in the mixture interact in such a way that the effective dipolar polarization gets increased and the components may form multimers leading to more effective dipoles. 
The dielectric data obtained i.e, $\varepsilon_{\text {static }}, \varepsilon^{*}, \varepsilon^{\prime}-j \varepsilon ”, \varepsilon_{\infty}$ and the data from LF-impedance analyzer is used to fit in an Argand diagram to calculate the relaxation time $(\tau)$. The distribution of relaxation time is witnessed from Cole-Cole arc plot ${ }^{15}$. Although Cole-Cole equations which signify the distribution of relaxation time, eventually a macroscopic relaxation time (predominant relaxation time) is measured using the equation.

$$
\omega \tau=\left(\frac{v}{u}\right)^{\frac{1}{1-\alpha}}
$$

Where $\alpha$ (distribution parameter), $\mu$ and $v$ values are determined from their respective Cole plots.

The excess inverse relaxation time $\left(\frac{1}{\tau}\right)^{E}$ which gives information regarding the dynamics of solute- solvent interaction and represents the average broadening of dielectric spectra, can be defined ${ }^{24}$ as

$$
\left(\frac{1}{\tau}\right)^{E}=\left(\frac{1}{\tau}\right)_{m}-\left[\left(\frac{1}{\tau}\right)_{1} x_{1}+\left(\frac{1}{\tau}\right)_{2} x_{2}\right]
$$

The thermodynamic parameters excess Gibb's energy of activation $\left(\Delta G^{*}\right)^{E}$, excess molar enthalpy of activation $\left(\Delta H^{*}\right)^{E}$ and excess molar entropy of activation $\left(\Delta S^{*}\right)^{E}$ at different mole fractions can be determined by fitting the Eyring rate equation ${ }^{25,26}$ as,

$$
\tau=\frac{\mathrm{h}}{\mathrm{kT}} \exp \left(\frac{\Delta \mathrm{G}^{*}}{\mathrm{RT}}\right)=\frac{\mathrm{h}}{\mathrm{kT}} \exp \left(\frac{\Delta \mathrm{H}^{*}-\mathrm{T} \Delta \mathrm{S}^{*}}{\mathrm{RT}}\right)
$$

Where $\mathrm{h}$ is the Planck's constant, $\mathrm{k}$ is the Boltzmann constant, $\mathrm{T}$ is the temperature in Kelvin and $\mathrm{R}$ is the gas constant.

Minimum energy structures of the pure monomers of $1 \mathrm{PN}, \mathrm{MB}, \mathrm{EB}$ and their equi molar hydrogen bonded complexes are obtained from Semi-empirical Hamiltonian quantum mechanical calculations such as Austin Model 1 (AM1), Parameterized Model number 3 (PM3) and Modified Neglect of Differential Overlap (MNDO) by converged geometry optimization procedure using PC Spartan and Argus lab Modeling softwares. ab-initio calculations have been carried out using PC Spartan modeling software and the geometry optimizations are done at the Hartree-Fock (HF) level using $6-31 \mathrm{G}^{*}$ basis set.

\section{Results and Discussion}

We studied $^{27}$ the temperature dependence on dielectric relaxation in pure and binary mixtures of propan-1-ol with methyl benzoate and ethyl benzoate at different frequencies to understand the nature of molecular orientation processes. The dielectric data is used to calculate Kirkwood effective correlation factor, corrective Kirkwood correlation factor, Bruggeman parameter, relaxation time and the thermodynamic parameters- Gibb's energy of activation, molar enthalpy and molar entropy of activation. Conformational analysis of the formation of hydrogen bond between equimolar mixtures of propan-1-ol with benzoates is studied from FT-IR spectra. The theoretical vibrational frequencies of the pure and equimolar hydrogen bonded systems are obtained from Hamiltonian quantum mechanical calculations using Spartan modeling software. The same data is used to study excess dielectric parameters and reporting in this communication. 
The dipole moment $(\mu)$ values for pure and equi molar systems (1 and 2$)$ at room temperature are determined experimentally with Higasi's method and theoretically with Hamiltonian quantum mechanical calculations (ab-initio and Semi-empirical) and the corresponding values are given in Table 1 . The dipole moments for these systems are measured experimentally by diluting them in non-polar solvent benzene. It is very clear from the experimental and theoretical dipole moment values, that there is an increase in the dipole moment of equi molar binary mixture when compared to the individual systems. This may be due to the formation of hydrogen bonding between the mixture systems ${ }^{13}$. The theoretical dipole moment values are in good agreement with the experimental values. The small deviation between the theoretical and experimental values may be due to the model dependency in theoretical case and in experimental case, the $\pi$ electron cloud of non-polar solvent benzene affecting the dipole moment value of the solute systems ${ }^{28}$.

Table 1. Experimental, Theoretical dipole moment $(\mu)$ and excess dipole moment $(\Delta \mu)$ values in Debye for pure 1PN, MB, EB and equi molar systems (1PN+MB and 1PN+EB) at room temperature (PCS- PC Spartan, AGS- Argus Lab)

\begin{tabular}{|c|c|c|c|c|c|c|c|c|c|c|c|c|c|c|c|c|}
\hline \multirow{5}{*}{ 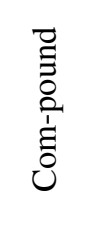 } & \multirow{3}{*}{\multicolumn{2}{|c|}{$\begin{array}{l}\text { Experi- } \\
\text { mental }\end{array}$}} & \multicolumn{14}{|c|}{ Theoretical } \\
\hline & & & \multirow{2}{*}{\multicolumn{2}{|c|}{$\begin{array}{c}\begin{array}{c}\mathrm{HF} \\
6-31 \mathrm{G}^{*}\end{array} \\
\mathrm{PCS} \\
\end{array}$}} & \multirow{2}{*}{\multicolumn{4}{|c|}{ AM1 }} & \multirow{2}{*}{\multicolumn{4}{|c|}{ PM3 }} & \multirow{2}{*}{\multicolumn{4}{|c|}{ MNDO }} \\
\hline & & & & & & & & & & & & & & & & \\
\hline & \multirow{2}{*}{$\mu$} & \multirow{2}{*}{$\Delta \mu$} & \multirow{2}{*}{$\mu$} & \multirow{2}{*}{$\Delta \mu$} & \multicolumn{2}{|c|}{ PCS } & \multicolumn{2}{|c|}{ AGS } & \multicolumn{2}{|c|}{ PCS } & \multicolumn{2}{|c|}{ AGS } & \multicolumn{2}{|c|}{ PCS } & \multicolumn{2}{|c|}{ AGS } \\
\hline & & & & & $\mu$ & $\Delta \mu$ & $\mu$ & $\Delta \mu$ & $\mu$ & $\Delta \mu$ & $\mu$ & $\Delta \mu$ & $\mu$ & $\Delta \mu$ & $\mu$ & $\mu$ \\
\hline $1 \mathrm{PN}$ & 1.57 & --- & 1.67 & --- & 1.53 & --- & 1.54 & --- & 1.42 & --- & 1.40 & --- & 1.38 & --- & 1.36 & --- \\
\hline MB & 1.81 & --- & 2.08 & --- & 2.10 & --- & 2.11 & --- & 2.07 & --- & 2.05 & --- & 2.22 & --- & 2.23 & --- \\
\hline EB & 2.05 & --- & 2.18 & --- & 2.12 & --- & 2.12 & --- & 2.09 & --- & 2.07 & --- & 2.25 & --- & 2.10 & --- \\
\hline $\begin{array}{c}1 \mathrm{PN}+ \\
\mathrm{MB}\end{array}$ & 2.96 & -0.42 & 3.51 & -0.24 & 3.19 & -0.44 & 3.37 & -0.28 & 3.08 & -0.41 & 3.04 & -0.41 & 3.01 & -0.59 & 2.96 & -0.63 \\
\hline $\begin{array}{c}1 \mathrm{PN}+ \\
\mathrm{EB}\end{array}$ & 3.21 & -0.4 & 3.12 & -0.73 & 33.44 & -0.21 & 3.48 & $-0.1 \varepsilon$ & 3.45 & -0.06 & 3.21 & -0.26 & 3.19 & -0.4 & 3.36 & -0.10 \\
\hline
\end{tabular}

The dipole moment values, measured for the pure and equi molar systems, are significantly affected by the variation in temperature and are given in Table 2.

Table 2. Experimental dipole moment $(\mu)$ and excess dipole moment $(\Delta \mu)$ values in Debye for pure $1 \mathrm{PN}, \mathrm{MB}, \mathrm{EB}$ and equi molar systems $(1 \mathrm{PN}+\mathrm{MB}$ and $1 \mathrm{PN}+\mathrm{EB})$ at temperatures (303 to 323$) \mathrm{K}$

\begin{tabular}{cccccccc}
\hline $\mathrm{T} / \mathrm{K}$ & $\begin{array}{c}1 \mathrm{PN} \\
\mu\end{array}$ & $\begin{array}{c}\mathrm{MB} \\
\mu\end{array}$ & $\begin{array}{c}\mathrm{EB} \\
\mu\end{array}$ & $\begin{array}{c}1 \mathrm{PN}+ \\
\mathrm{MB} \mu\end{array}$ & $\begin{array}{c}1 \mathrm{PN}+\mathrm{MB} \\
(\Delta \mu)\end{array}$ & $\begin{array}{c}1 \mathrm{PN}+\mathrm{EB} \\
\mu\end{array}$ & $\begin{array}{c}1 \mathrm{PN}+\mathrm{EB} \\
(\Delta \mu)\end{array}$ \\
\hline 303 & 1.57 & 1.81 & 2.05 & 2.96 & -0.42 & 3.21 & -0.41 \\
308 & 1.59 & 1.83 & 2.08 & 2.98 & -0.44 & 3.24 & -0.43 \\
313 & 1.60 & 1.84 & 2.10 & 3.09 & -0.35 & 3.27 & -0.43 \\
318 & 1.58 & 1.86 & 2.12 & 3.19 & -0.25 & 3.31 & -0.39 \\
323 & 1.62 & 1.88 & 2.14 & 3.30 & -0.20 & 3.32 & -0.44 \\
\hline
\end{tabular}

The excess dipole moment $(\Delta \mu)$ values obtained theoretically and experimentally at different temperatures are given in Tables 1 and 2. It is observed that in all cases the values of $\Delta \mu$ are negative, which indicates the absence of any contribution from ionic structure of 
the binary system to the total dipole moment since the formation of an ionic structure involves a very high positive value for $\Delta \mu^{29}$. The excess dipole moment value is a qualitative index for the presence of hydrogen bonding in both the systems (1 and 2).

The long range and short-range interactions between dipoles can be studied from the thermo dynamical parameter excess Helmholtz free energy $\left(\Delta \mathrm{F}^{\mathrm{E}}\right)$ and its constituent parameters $\Delta \mathrm{F}_{o r}{ }^{\mathrm{E}}, \Delta \mathrm{F}_{r r}{ }^{\mathrm{E}}, \Delta \mathrm{F}_{12}{ }^{\mathrm{E} 30}$. The value of $\Delta \mathrm{F}_{o r}{ }^{\mathrm{E}}$ represents the long range interaction between the dipoles in the mixture. In both systems ( 1 and 2$)$, the positive values of $\Delta \mathrm{F}_{o r}{ }^{\mathrm{E}}$ indicate the existence of attractive forces between the dipoles and the larger separation between the interacting molecules, which are given in Table 3. Negative values of $\Delta \mathrm{F}_{o r}{ }^{\mathrm{E}}$ indicate the repulsive force between dipoles and interacting molecules are at closer distance. In system 1 , the values of $\Delta \mathrm{F}_{o r}{ }^{\mathrm{E}}$ are positive for low concentration of methyl benzoate in $1 \mathrm{PN}$ and negative for remaining concentrations but in system 2 , the values of $\Delta \mathrm{F}_{o r}{ }^{\mathrm{E}}$ are positive up to equimolar concentration and negative for remaining concentrations. For both the systems, as the temperature increases the values of $\Delta \mathrm{F}_{o r}{ }^{\mathrm{E}}$ are also increases for all the mole fractions. This shows that the strength of dipole-dipole interaction depends on the concentration and temperature of the mixture. The values of $\Delta \mathrm{F}_{o r}{ }^{\mathrm{E}}$ for system 2 are greater than system 1 . This may be due to the interaction of the compounds in the mixture which produces structural changes.

Table 3. Values of $\Delta \mathrm{F}_{o r}^{E}$ in Joule/ mole with mole fraction ( $\left.x_{2}\right)$ of System 1 and System 2 at temperatures (303 to 323$) \mathrm{K}$

\begin{tabular}{ccccccccccc}
\hline & \multicolumn{2}{c}{$\mathrm{T}=303 \mathrm{~K}$} & \multicolumn{2}{c}{$\mathrm{T}=308 \mathrm{~K}$} & \multicolumn{2}{c}{$\mathrm{T}=313 \mathrm{~K}$} & \multicolumn{2}{c}{$\mathrm{T}=318 \mathrm{~K}$} & \multicolumn{2}{c}{$\mathrm{T}=323 \mathrm{~K}$} \\
\cline { 2 - 11 }$x_{2}$ & System & System & System & System & System & System & System & System & System & System \\
& 1 & 2 & 1 & 2 & 1 & 2 & 1 & 2 & 1 & 2 \\
\hline 0 & 00.0000 & 00.0000 & 00.0000 & 00.0000 & 00.0000 & 00.0000 & 00.0000 & 00.0000 & 00.0000 & 00.0000 \\
0.1 & 13.1903 & 13.5517 & 14.6358 & 19.5747 & 14.6057 & 22.8874 & 14.6358 & 24.6943 & 15.0575 & 25.2966 \\
0.2 & 12.7386 & 13.2506 & 14.3949 & 18.6713 & 15.4791 & 24.6943 & 16.0512 & 27.7058 & 16.2621 & 28.9104 \\
0.3 & -00.2108 & 15.0575 & 01.8671 & 16.5632 & 02.3790 & 15.6598 & 04.2763 & 12.9494 & 05.4207 & 11.4437 \\
0.4 & -22.4959 & 14.1540 & -20.8998 & 15.9609 & -15.8103 & 17.7678 & -12.4374 & 17.1655 & -08.4322 & 18.6713 \\
0.5 & -26.6517 & 02.1080 & -25.5375 & 00.9034 & -24.8749 & 01.2046 & -26.0193 & 01.2046 & -30.4161 & 02.1080 \\
0.6 & -46.1060 & -06.0230 & -43.2451 & -03.3126 & -42.7633 & -00.6023 & -40.0529 & 02.1080 & -40.3541 & 03.0115 \\
0.7 & -66.3734 & -36.7403 & -61.3743 & -32.2230 & -53.9058 & -27.4046 & -45.9253 & -26.2000 & -43.9679 & -24.092 \\
0.8 & -63.5125 & -47.2805 & -54.5984 & -44.5702 & -53.1529 & -40.6552 & -48.1538 & -38.2460 & -47.2805 & -34.3311 \\
0.9 & -45.8049 & -29.2115 & -42.1007 & -24.3931 & -38.6676 & -21.6828 & -34.4214 & -22.5862 & -36.1380 & -19.2736 \\
1 & 00.0000 & 00.0000 & 00.0000 & 00.0000 & 00.0000 & 00.0000 & 00.0000 & 00.0000 & 00.0000 & 00.0000 \\
\hline
\end{tabular}

The values of $\Delta \mathrm{F}_{r r}{ }^{\mathrm{E}}$ predict the information on the short range interaction between similar molecules. In both the systems, the values of $\Delta \mathrm{F}_{r r}{ }^{\mathrm{E}}$ are highly positive at all mole fractions and are given in Table 4, indicating the existence of short range interaction through hydrogen bonding. The values of $\Delta \mathrm{F}_{r r}{ }^{\mathrm{E}}$ for system 2 are greater than system 1 indicating the strong short range interaction between the components of similar molecules of the system 2 . 
Table 4. Values of $\Delta \mathrm{F}_{r r}^{E}$ in Joule/ mole with mole fraction $\left(x_{2}\right)$ of System 1 and System 2 at temperatures (303 to 323 ) $\mathrm{K}$

\begin{tabular}{ccccccccccc}
\hline & \multicolumn{2}{c}{$\mathrm{T}=303 \mathrm{~K}$} & \multicolumn{2}{c}{$\mathrm{T}=308 \mathrm{~K}$} & \multicolumn{2}{c}{$\mathrm{T}=313 \mathrm{~K}$} & \multicolumn{2}{c}{$\mathrm{T}=318 \mathrm{~K}$} & \multicolumn{2}{c}{$\mathrm{T}=323 \mathrm{~K}$} \\
\cline { 2 - 11 }$x^{2}$ & System & System & System & System & System & System & System & System & System & System \\
& 1 & 2 & 1 & 2 & 1 & 2 & 1 & 2 & 1 & 2 \\
\hline 0 & 00.0000 & 00.0000 & 00.0000 & 00.0000 & 00.0000 & 00.0000 & 00.0000 & 00.0000 & 00.0000 & 00.0000 \\
0.1 & 43.1547 & 44.8412 & 45.8350 & 58.3628 & 44.7508 & 64.6569 & 43.8474 & 66.4035 & 43.4438 & 65.7711 \\
0.2 & 74.5045 & 80.9491 & 77.1847 & 91.6098 & 77.7870 & 101.9995 & 77.5160 & 105.7638 & 76.4017 & 104.4087 \\
0.3 & 92.6939 & 136.3306 & 95.8560 & 136.9329 & 94.5912 & 130.5786 & 96.5788 & 120.6406 & 97.5424 & 112.8409 \\
0.4 & 99.1988 & 182.3162 & 101.2466 & 181.2320 & 107.2696 & 177.7086 & 110.8232 & 170.9628 & 116.0632 & 166.0239 \\
0.5 & 125.4590 & 187.3153 & 125.7301 & 181.0513 & 123.8027 & 174.7272 & 120.3997 & 168.7644 & 114.8586 & 161.9283 \\
0.6 & 107.0889 & 164.9699 & 108.9259 & 162.5005 & 106.8179 & 158.5554 & 106.3997 & 155.5740 & 106.9684 & 148.4669 \\
0.7 & 72.9987 & 105.3422 & 74.4442 & 104.5893 & 76.0704 & 102.0296 & 78.1785 & 98.7772 & 79.2626 & 94.6213 \\
0.8 & 38.8483 & 55.0803 & 40.7757 & 53.5444 & 40.3239 & 51.6773 & 40.7154 & 49.3584 & 41.0467 & 47.3407 \\
0.9 & 10.1186 & 16.1416 & 10.9618 & 15.6598 & 11.0522 & 14.9972 & 11.2027 & 14.5455 & 11.3232 & 13.0397 \\
0.1 & 00.0000 & 00.0000 & 00.0000 & 00.0000 & 00.0000 & 00.0000 & 00.0000 & 00.0000 & 00.0000 & 00.0000 \\
\hline
\end{tabular}

The values of $\Delta \mathrm{F}_{12}{ }^{\mathrm{E}}$ predict the information on the strength of interaction between unlike molecules. In both the systems, the values of $\Delta \mathrm{F}_{12}{ }^{\mathrm{E}}$ have appreciable change with respect to concentration and temperature, are given in Table 5. This reveals that hetero association is involving between the compounds which are varying with concentration and temperatures.

Table 5. Values of $\Delta \mathrm{F}_{12}^{E}$ in Joule/ mole with mole fraction $\left(x_{2}\right)$ of System 1 and System 2 at temperatures (303 to 323$) \mathrm{K}$

\begin{tabular}{|c|c|c|c|c|c|c|c|c|c|c|}
\hline \multirow{3}{*}{$x_{2}$} & \multicolumn{2}{|c|}{$\mathrm{T}=303 \mathrm{~K}$} & \multicolumn{2}{|c|}{$\mathrm{T}=308 \mathrm{~K}$} & \multicolumn{2}{|c|}{$\mathrm{T}=313 \mathrm{~K}$} & \multicolumn{2}{|c|}{$\mathrm{T}=318 \mathrm{~K}$} & \multicolumn{2}{|c|}{$\mathrm{T}=323 \mathrm{~K}$} \\
\hline & ystem & System & System & System & System & System & System & System & System & System \\
\hline & 1 & 2 & 1 & 2 & 1 & 2 & 1 & 2 & 1 & 2 \\
\hline 0 & 00.0000 & 00.0000 & 00.0000 & 00.0000 & 00.0000 & 00.0000 & 00.0000 & 00.0000 & 00.0000 & $\overline{00.0000}$ \\
\hline 0.1 & 00.9173 & 01.1323 & 1.0249 & 01.76 & 00.8395 & 01.9902 & 00.9000 & 02.0915 & 00.8360 & 02.0273 \\
\hline 0.2 & 02.6945 & 02.9091 & 02.8205 & 03.8669 & 02.6288 & 04.5 & 02.7218 & 04.8 & 02.6039 & 04.6672 \\
\hline 0.3 & 04.0743 & 07.1977 & 04.1967 & 07.0 & 03.9549 & 06.4580 & 04.2339 & 05.8547 & 04.2399 & 05.1666 \\
\hline 0.4 & 04.4631 & 04.6599 & 04.4423 & 04.1202 & 4.8211 & 03.5890 & 05.0108 & 03.5356 & 05.2529 & 03.0285 \\
\hline 0.5 & 02.2165 & -08.4738 & 02.3892 & -07.7962 & 01.8530 & -07.5579 & 01.9851 & -07.2970 & 02.4356 & -07.0941 \\
\hline 0.6 & -05.1186 & 29.029 & -05.8334 & -29.8438 & -05.8063 & -30.2912 & -06.4419 & -30.788 & -06.5477 & -29.6860 \\
\hline 0.7 & -09.7080 & -29.51 & -10.973 & -30.6160 & -13.0503 & -31.5484 & -15.5178 & -30.947 & -16.6009 & -30.2181 \\
\hline 0.8 & & 24. & & -25 & -14.2371 & -24 & -1 & -24 & -1 & -24.5865 \\
\hline 0.9 & -06. & 12. & -0 & -13.2430 & -07.3298 & -13.0686 & -07.6779 & -12.3885 & -07.5748 & -12.1759 \\
\hline 1 & 00.0000 & 00.0000 & 00.0000 & 00.0000 & 00.0000 & 00.0000 & 00.0000 & 00.0000 & 00.0000 & 00.0000 \\
\hline
\end{tabular}

Finally the high positive values of $\Delta \mathrm{F}^{\mathrm{E}}$, as reported in Table 6 , for both the systems (1 and 2) indicate the formation of $\beta$ - clusters with anti-parallel alignment. Due to the formation of $\beta$ - clusters the effective dipole moment will be decreased when compared to the sum of individual systems and thereby it destructs the angular correlation between non ideal molecules which may decrease its internal energy ${ }^{31}$. The decrement in the internal energy of molecule leads to the increment in the excess free energy value. The negative values of $\Delta \mathrm{F}^{\mathrm{E}}$ indicate the formation of $\alpha$-clusters. Due to the formation of these $\alpha$-clusters the effective dipole moment will be increased which increases the internal energy.

The excess permittivity $\left(\varepsilon^{E}\right)$ is another dielectric parameter, which gives information about the interaction between the components of the mixture. Mehrotra et. al. ${ }^{32}$ had pointed 
out that the change in the value of $\varepsilon^{E}$ with concentration is due to the interaction between dissimilar molecules which may produce structural changes. In system 1 and system 2 , negative values of $\varepsilon^{E}$ are obtained for all mole fractions at different temperatures ${ }^{33}$ and are shown in Figures 1 and 2 respectively. These negative values indicate that the molecules in the mixture form multimers through Hydrogen bonding in such a way that the effective dipole moment gets reduced ${ }^{34}$. The more negative deviations in $\varepsilon^{E}$ values of system 2 compared to system 1 indicate that the strength of hydrogen bond formation is more in system 2 than in system 1 .

Table 6. Values of $\Delta \mathrm{F}^{E}$ in Joule/ mole with mole fraction (惀) of System 1 and System 2 at temperatures (303 to 323 ) $\mathrm{K}$

\begin{tabular}{|c|c|c|c|c|c|c|c|c|c|c|}
\hline \multirow{3}{*}{$x_{2}$} & \multicolumn{2}{|c|}{$\mathrm{T}=303 \mathrm{~K}$} & \multicolumn{2}{|c|}{$\mathrm{T}=308 \mathrm{~K}$} & \multicolumn{2}{|c|}{$\mathrm{T}=313 \mathrm{~K}$} & \multicolumn{2}{|c|}{$\mathrm{T}=318 \mathrm{~K}$} & \multicolumn{2}{|c|}{$\mathrm{T}=323 \mathrm{~K}$} \\
\hline & $\mathrm{m}$ & System & $\mathrm{em}$ & System & System & System & System & System & System & System \\
\hline & 1 & 2 & 1 & 2 & 1 & 2 & 1 & 2 & 1 & 2 \\
\hline 0 & 00.0000 & 00.0000 & 00.0000 & 00.0000 & 00.0000 & 00.0000 & 000 & 00.0000 & 00.0000 & 00.0000 \\
\hline 0.1 & 57.2623 & 59.5252 & 57 & 79.7067 & 60.196 & 89.5 & 832 & 93.1893 & 373 & 93.095 \\
\hline 0.2 & 89.9376 & 97.1091 & 94.4001 & 114.148 & 95.8949 & 85 & .2890 & 8.2777 & 95.2677 & 137.9863 \\
\hline 0.3 & 96.5574 & 158.5858 & 101.9198 & 160.526 & 100.9251 & 152.64 & 105. & 139.4447 & 107 & 129.4512 \\
\hline 0.4 & 81.1660 & 201.1301 & 83.78 & 201.3131 & & 199.0 & 103.3 & 1.6639 & 112.8839 & 187.7237 \\
\hline 0.5 & & & & & & & 90 & 162.672 & 86. & 156.9422 \\
\hline 0.6 & & & & & & 127 & 60 & 36 & 60. & 121.7924 \\
\hline 0.7 & & 39. & 02.0969 & & 09 . & 43.0766 & 16.7354 & 41. & 18.6938 & 40.3112 \\
\hline 0. & & -17.1529 & -28.0281 & -16.0562 & -27.0661 & -13.88 & -22.7626 & -13.6681 & -22.1471 & -11.5769 \\
\hline 0.9 & 3206 & -25.9048 & -38.1442 & -21.9763 & -34.9 & -19.75 & -30.8966 & -20.4292 & -32.3896 & -18.4098 \\
\hline 1 & 00.0000 & 00.0000 & 00.0000 & 00.0000 & 00.0000 & 00.0000 & 00.0000 & 00.0000 & 00.0000 & 00.0000 \\
\hline
\end{tabular}

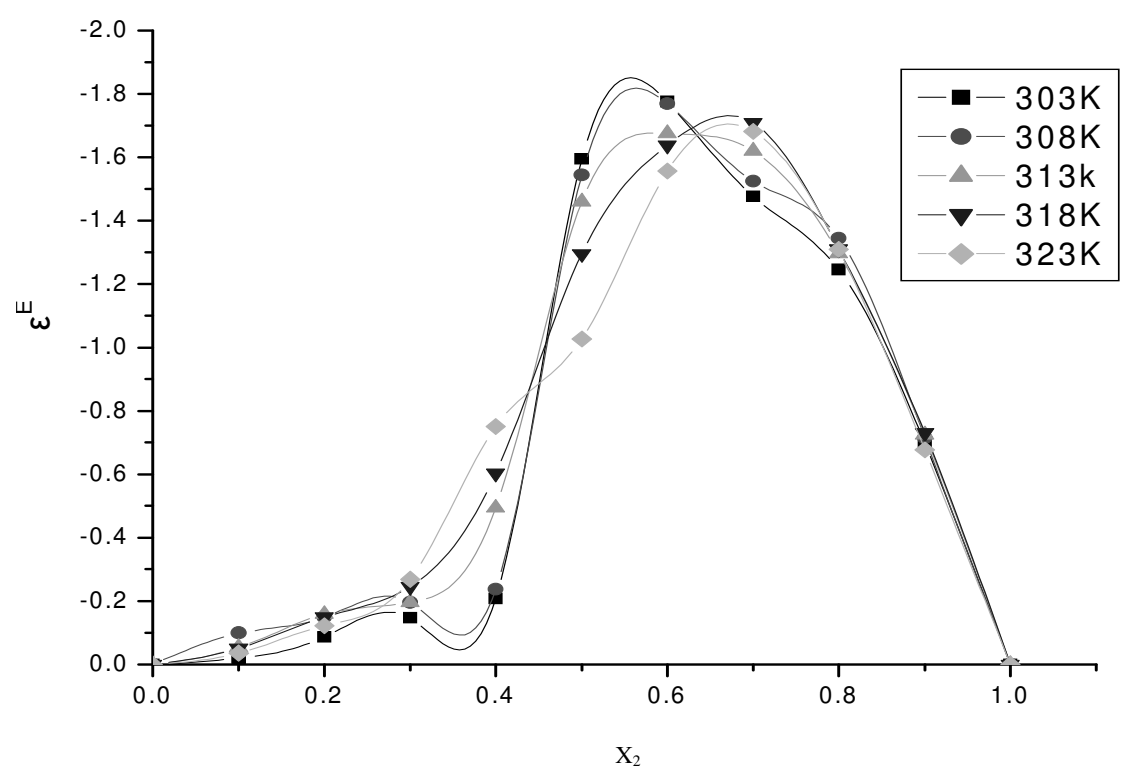

Figure 1. Plot of excess permittivity $\left(\varepsilon^{E}\right)$ with mole fraction $\left(x_{2}\right)$ of methyl benzoate in propan-1-ol for different temperatures 


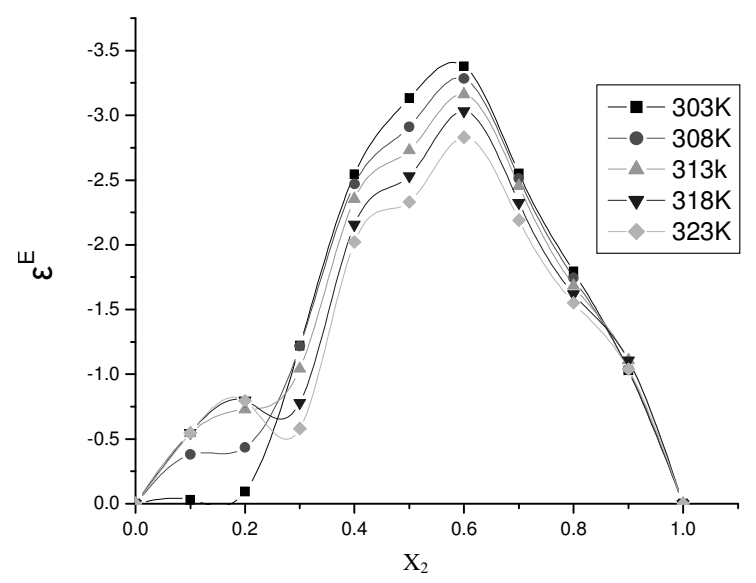

Figure 2. Plot of excess permittivity $\left(\varepsilon^{E}\right)$ with mole fraction $\left(x_{2}\right)$ of ethyl benzoate in propan-1-ol for different temperatures

The relaxation times $(\tau)$ of pure 1PN are higher and is due to the formation of intra molecular hydrogen bonding between one alcohol molecule and another $(\mathrm{R}-\mathrm{O}-\mathrm{H} . . \mathrm{OH}-\mathrm{R})$, which leads to the formation of self associated groups. The increase in the number of self associated groups causes to absorb more electromagnetic energy. Due to this molecules relax very slowly leading to higher relaxation times ${ }^{35}$. But the relaxation times of pure MB and EB are very low ${ }^{29}$ compared to pure 1PN. The relaxation times of pure EB are greater than that of pure MB due to the increase in molecular size and effective radius of the rotating unit ${ }^{36}$. The relaxation times are found to decrease as the concentration of MB and EB increases in $1 \mathrm{PN}$ at all temperatures are given in Table 7.

Table 7. Values of relaxation time ( $₫$ pico second) with mole fraction $(\triangle \varnothing)$ of System 1 and System 2 at temperatures (303 to 323 ) $\mathrm{K}$

\begin{tabular}{|c|c|c|c|c|c|c|c|c|c|c|}
\hline \multirow{3}{*}{2} & \multicolumn{2}{|c|}{$\mathrm{T}=303 \mathrm{~K}$} & \multicolumn{2}{|c|}{$\mathrm{T}=308 \mathrm{~K}$} & \multicolumn{2}{|c|}{$\mathrm{T}=313 \mathrm{~K}$} & \multicolumn{2}{|c|}{$\mathrm{T}=318 \mathrm{~K}$} & \multicolumn{2}{|c|}{$\mathrm{T}=323 \mathrm{~K}$} \\
\hline & tem & Syst & System & Syste & System & Syst & a & Syst & 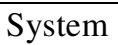 & yst \\
\hline & 1 & 2 & 1 & 2 & 1 & 2 & 1 & 2 & 1 & 2 \\
\hline 0 & 246.23 & 46.2 & 6.72 & 16.72 & 6.71 & 186.7 & 9.25 & 169. & 57.68 & 157. \\
\hline & & & & & & & & & & \\
\hline & & & & & & & & & & \\
\hline & & & & & & & & & & \\
\hline & & & & & & & & & & 120.15 \\
\hline 0.5 & & 121.24 & & 114 & & & & & & 96.76 \\
\hline & & & & & & 86 & & & 66 & 76.34 \\
\hline & & & & & & & & & & 21 \\
\hline & & & & & & & & & & .27 \\
\hline 0.9 & & & & & & & & & & 13.76 \\
\hline 1 & 2.82 & 13.42 & 1.49 & 11.81 & 8.25 & 10.24 & 7.28 & 07.94 & 5.71 & 07.13 \\
\hline
\end{tabular}

At high concentrations of alcohol in the mixture, there are a large number of 1PN molecules surrounding the benzoate molecules and these associative alcohol molecules are forming hydrogen bond with the benzoate molecules. Thus dipole- dipole interaction occurs in such ways that the effective dipole moment gets increased and linear $\alpha$-multimers are 
formed $^{37}$. At low concentration of $1 \mathrm{PN}$ in the mixtures, there are only a small number of alcohol molecules to enable dipole-dipole interaction through hydrogen bonding with the nonassociative benzoate molecules. As a result, weak intermolecular interaction occurs. The relaxation time increases with increasing alkyl chain length of benzoate indicating that the degree of cooperation for reorientation of the molecules increases with increasing length and the bulk of cluster increases. So the formation of hydrogen bonding between hydroxyl group $(-\mathrm{OH})$ of $1 \mathrm{PN}$ and $-\mathrm{CH}$ group of benzoates restricts the free internal rotation of the molecules.

The excess inverse relaxation times are determined from the data of relaxation times obtained from the Cole-Cole plots. The calculated values of excess inverse relaxation time $\left(\frac{1}{\tau}\right)^{E}$, for both the systems, are negative and are presented in Figures 3 and 4 for the systems 1 and 2 respectively. These negative values indicate the slower rotation of dipoles due to the formation of hydrogen-bonded structures producing a field, which hinders the effective dipole rotation ${ }^{16,24}$.

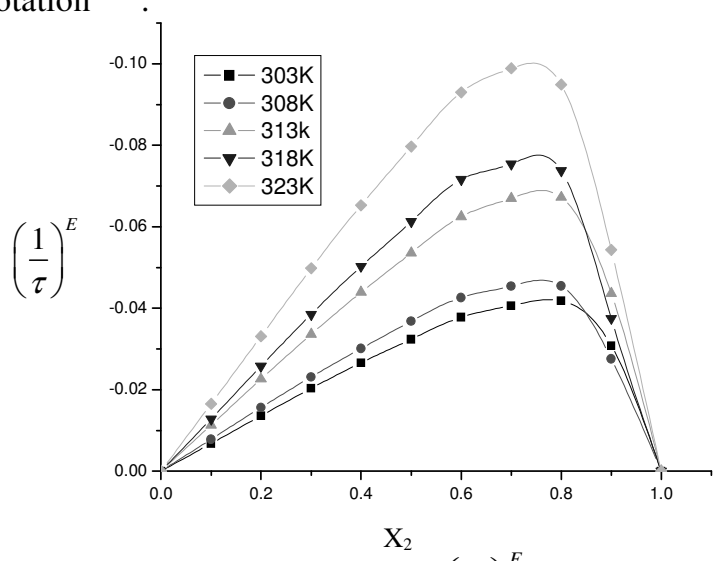

Figure 3. Plot of excess inverse relaxation time $\left(\left(\frac{1}{\tau}\right)^{E}\right)$ with mole fraction $\left(x_{2}\right)$ of methyl benzoate in propan-1-ol for different temperatures

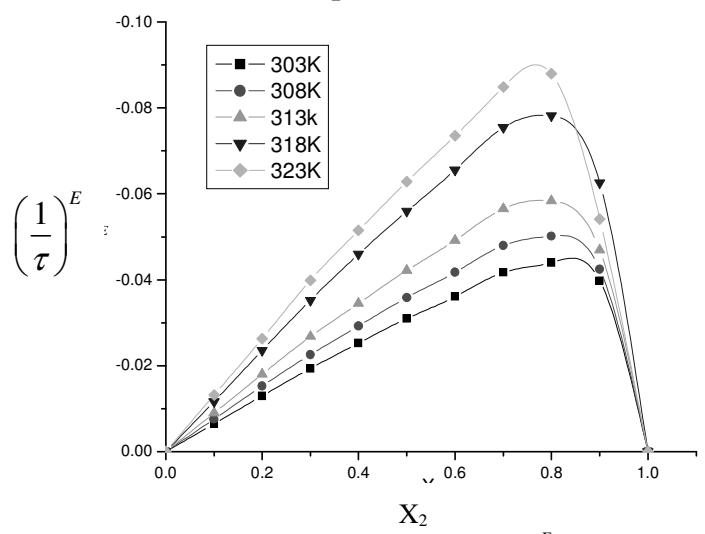

Figure 4. Plot of excess inverse relaxation time $\left(\left(\frac{1}{\tau}\right)^{E}\right)$ with mole fraction $\left(x_{2}\right)$ of ethyl benzoate in propan-1-ol for different temperatures 
The variation of excess Gibb's energy of activation $\left(\Delta G^{*}\right)^{E}$ values, with mole fraction and temperature, for system 1 and system 2 are shown in Figures 5 and 6 respectively. The values of $\left(\Delta G^{*}\right)^{E}$ are positive, in both the systems, which indicates the presence of interaction between the molecules of the mixtures. The magnitude of $\left(\Delta G^{*}\right)^{E}$ is an excellent indicator of the strength of interaction between unlike molecules in liquid mixtures ${ }^{38}$. It was reported by some researchers ${ }^{39}$ attributed the increasing positive values of $\left(\Delta G^{*}\right)^{E}$ in few binary liquid mixtures, to hydrogen bond formation between unlike molecules, which supports the present investigation. Further, it is observed that $\left(\Delta G^{*}\right)^{E}$ values of system 2 are greater than that of system 1 indicating a stronger bond formation in system 2 . The excess molar enthalpy $\left(\Delta H^{*}\right)^{E}$ and excess molar entropy $\left(\Delta S^{*}\right)^{E}$ values are shown in Figures 7 and 8 respectively. The negative values of $\left(\Delta H^{*}\right)^{E}$, for both the systems, show that strong attractive interactions are present between unlike molecules of the mixtures ${ }^{40}$. The formation of hydrogen bonding between the components in system 1 and system 2 is also justified by the negative values of excess molar entropy ${ }^{16}$.

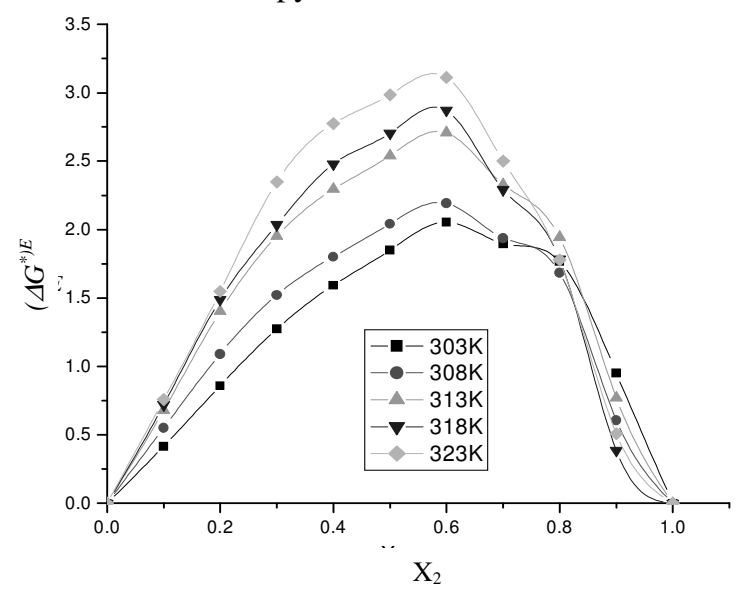

Figure 5. Plot of excess Gibb's energy of activation $\left(\Delta G^{*}\right)^{E}$ with mole fraction $\left(x_{2}\right)$ of methyl benzoate in propan-1-ol for different temperatures

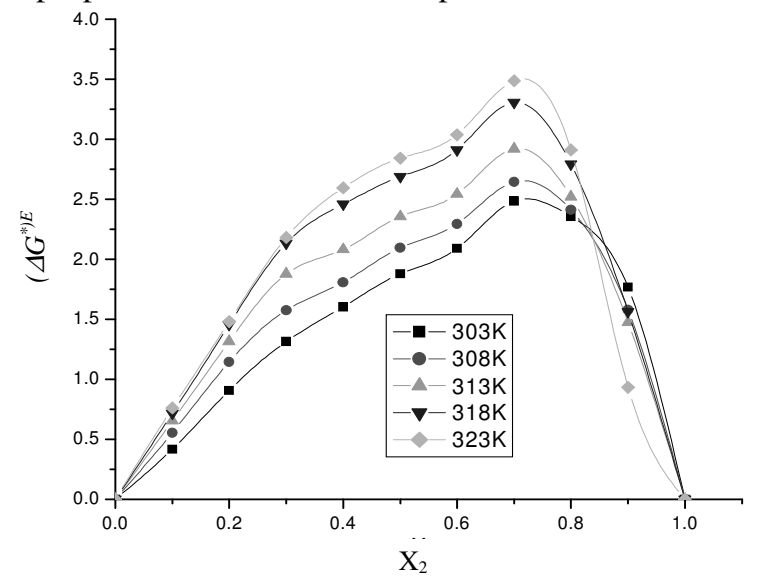

Figure 6. Plot of excess Gibb's energy of activation $\left(\Delta G^{*}\right)^{E}$ with mole fraction $\left(x_{2}\right)$ of ethyl benzoate in propan-1-ol for different temperatures 


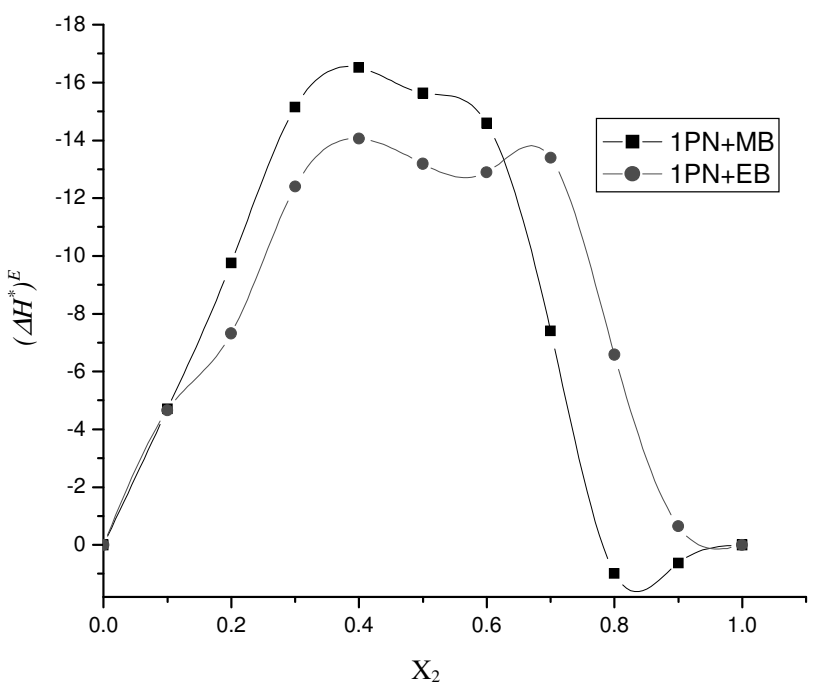

Figure 7. Plot of excess molar enthalpy $\left(\Delta H^{*}\right)^{E}$ with mole fraction $\left(x_{2}\right)$ of methyl and ethyl benzoates in propan-1-ol for different temperatures

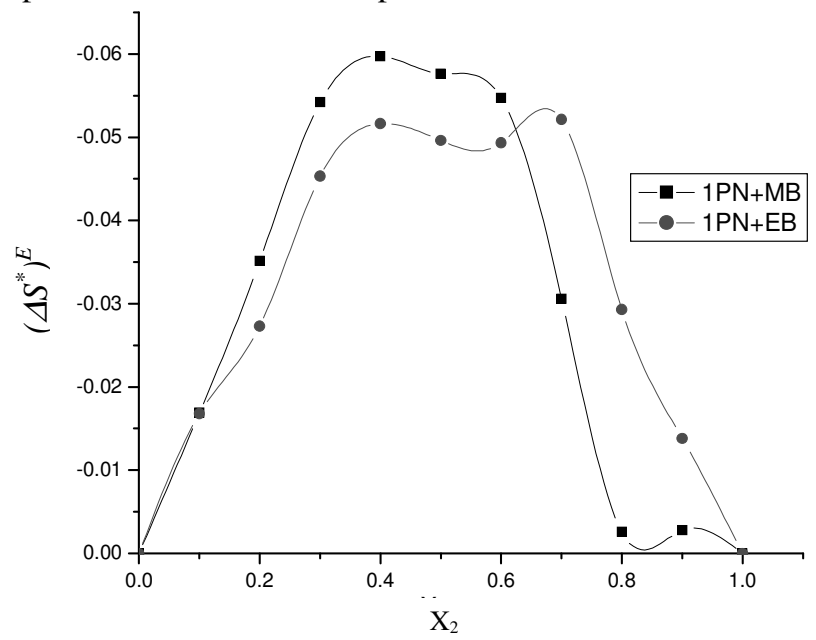

Figure 8. Plot of excess molar entropy $\left(\Delta S^{*}\right)^{E}$ with mole fraction $\left(\mathrm{x}_{2}\right)$ of methyl and ethyl benzoates in propan-1-ol for different temperatures

The hydrogen bonding energy or the interaction energy $(\Delta \mathrm{E})$ values are calculated, for both the systems, using Hamiltonian quantum mechanical calculations and are given in Table 8 . The interaction energy between the components of a mixture should be negative if that mixture is stabilized by the presence of hydrogen bonds. Moreover the magnitude of the interaction energy would be a measure of the hydrogen-bonding stabilization. The hydrogen bonding energies in the present study are found to be negative in both the binary complexes, in all theoretical models, indicating the formation of hydrogen bonding ${ }^{28}$. The optimized converged geometrical structures of hydrogen bonded systems 1 and 2, which are obtained from Hamiltonian quantum mechanical calculations, are shown in Figures 9(a), 9(b) respectively. 
Table 8. Heat of formation (E, kcal mol $\left.{ }^{-1}\right)$ and hydrogen bonding energy $\left(\Delta \mathrm{E}, \mathrm{kcal} \mathrm{mol}^{-1}\right)$ (PCS- PC Spartan, AGS- Argus Lab)

\begin{tabular}{|c|c|c|c|c|c|c|c|c|c|c|c|c|}
\hline \multirow{3}{*}{$\begin{array}{l}\text { Com- } \\
\text { pound }\end{array}$} & \multicolumn{4}{|c|}{ AM1 } & \multicolumn{4}{|c|}{ PM3 } & \multicolumn{4}{|c|}{ MNDO } \\
\hline & \multicolumn{2}{|c|}{ PCS } & \multicolumn{2}{|c|}{ AGS } & \multicolumn{2}{|c|}{ PCS } & \multicolumn{2}{|c|}{ AGS } & \multicolumn{2}{|c|}{ PCS } & \multicolumn{2}{|c|}{ AGS } \\
\hline & $\mathrm{E}$ & $\Delta \mathrm{E}$ & $\mathrm{E}$ & $\Delta \mathrm{E}$ & $\mathrm{E}$ & $\Delta \mathrm{E}$ & $\mathrm{E}$ & $\Delta \mathrm{E}$ & $\mathrm{E}$ & $\Delta \mathrm{E}$ & $\mathrm{E}$ & $\Delta \mathrm{E}$ \\
\hline $\begin{array}{c}\text { propan- } \\
1 \text {-ol }\end{array}$ & -69.53 & --- & -67.51 & --- & -66.35 & --- & -60.83 & --- & -67.72 & --- & -65.88 & --- \\
\hline $\begin{array}{c}\text { methyl } \\
\text { benzoate }\end{array}$ & -61.18 & --- & -59.65 & --- & -57.90 & --- & -57.07 & --- & -57.99 & --- & -55.45 & --- \\
\hline $\begin{array}{c}\text { ethyl } \\
\text { benzoate } \\
\text { propan- }\end{array}$ & -66.96 & --- & -65.07 & --- & -62.68 & --- & -57.07 & --- & -63.20 & --- & -55.45 & --- \\
\hline $\begin{array}{c}\text { 1-ol + } \\
\text { methyl } \\
\text { benzoate }\end{array}$ & -133.06 & -2.34 & -130.45 & -3.28 & -125.19 & -0.94 & -121.21 & -3.30 & -127.76 & -2.05 & -123.62 & -2.28 \\
\hline $\begin{array}{c}\text { propan- } \\
1-\text { ol + } \\
\text { ethyl } \\
\text { benzoate }\end{array}$ & -139.57 & -3.08 & -135.50 & -2.91 & -129.71 & -0.68 & -125.55 & -2.91 & -132.74 & -1.81 & -128.51 & -7.18 \\
\hline
\end{tabular}

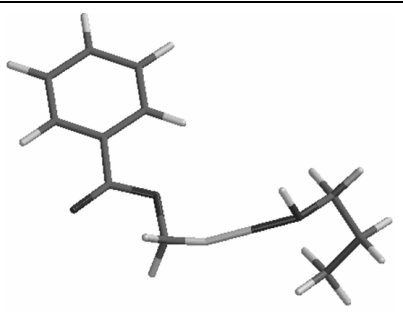

(a)

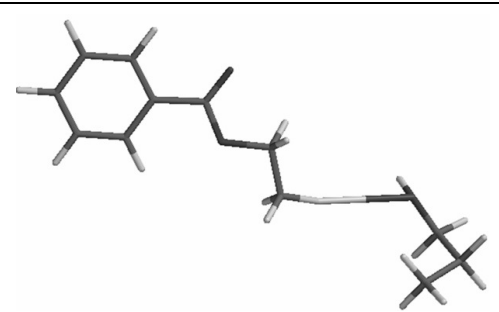

(b)

Figure 9. Optimized converged geometrical structure of hydrogen bonded methyl benzoate and propan-1-ol. methyl benzoate $+1 \mathrm{PN}$, (b) ethyl benzoate $+1 \mathrm{PN}$ (Red: Oxygen, Black: Carbon, White: Hydrogen)

\section{Conclusion}

The excess dielectric and thermodynamical parameters - dipole moment, excess dipole moment, excess Helmholtz free energy, excess permittivity, relaxation time, excess inverse relaxation and excess thermodynamical values are computed for the pure and binary mixtures of system 1(1PN + Methyl Benzoate) and system 2 (1PN + Ethyl Benzoate) for various mole fractions at different temperatures. The formation of Hydrogen bonding between the mixture systems is identified by studying the variations in the parameters determined. The values of dipole moment and excess dipole moment are determined theoretically using quantum mechanical calculations and are in good agreement with the experimental values.

\section{Acknowledgement}

The authors gratefully acknowledge the University Grants Commission, New Delhi for providing financial assistance through the Major Research Project No. F: 34-12\2008 (SR) dated 30-12-2008 and UGC DRS LEVEL III program No.F.530/1/DRS/2009 (SAP-I), dated 09-02-2009 New Delhi, to the department of Physics. 


\section{References}

1. Gupta K K, Bansal A K, Singh P J and Sharma K S, Indian J Pure Appl Phys., 2003, 41, 57-63.

2. Reddy R R, Rama Gopal K, Narasimhulu K, Siva Sankara Reddy L, Raghavendra Kumar K, Venkatesulu A and Krishna Reddy C V, J Mol Liq., 2008, 140, 48-53.

3. Thenappan T and Subramanian M, Indian J Pure Appl Phys., 2001, 39(11), 694-697.

4. Ghanadzaaeh A, Ghanadzadeh H, Sariri R and Ebrahimi L, J Chem Thermodynamic. 2005, 37(4), 357-362.

5. $\quad$ Nath G, Sahu S and Paikaray R, Indian J Phys., 2009, 83(4), 429-436.

6. $\quad$ Sengwa R J, Vinita K and Sonu S, J Sol Chem., 2009, 38, 763-769.

7. Aparicio S, Alcalde R, Davila M J, Garcia B and Leal J M, J Phys Chem B.,.2007, 111, 4417-4431.

8. Chitra M, Subramanyam B and Murthy V R K, Indian J Pure Appl Phys., 2001, 39, 461-466.

9. George A J, An introduction to hydrogen bonding, Oxford University Press: Oxford, England, 1997.

10. Garcia B, Alcalde R, Aparicio S and Leal J M, Phys Chem Chem Phys., 2002, 4, 5833 - 5840.

11. Vishwam T, Subramanian V, Subbaiah D V and Murthy V R K, Mol Phys., 2008, 106(1), 95-101.

12. Higasi K, Koga Y and Nakamura M, Bull Chem Soc Japan, 1971, 44, 988-992.

13. Vishwam T, Chitra M, Subramanian V and Murthy V R K, J Mol Phys., 2007, 105(17-18), 2411-2417.

14. Parthipan G and Thenappan T, J Mol Liq., 2007, 133, 1-6.

15. Cole K S and Cole R H, J Chem Phys., 1941, 9, 341- 351.

16. Dharmalingam K, Ramachandran K, Sivagurunathan P, Prabhakar Undre B, Khirade P W and Mehrotra S C, Chem. Pap., 2007, 61(4), 300-307.

17. Spartan version 5.1.1., Wave function Inc., 18401 Von Kaman Ave., Suite 370, Irvine, CA, USA, 1999.

18. Mark A, Thompson, Argus Lab 4.0.1, Planaria Software LLC, Seattle, WA, 1997.

19. Hill N E, Vaughan W E, Price A H and Davies M, Dielectric properties and molecular behavior, Van Nostard-Reinhold, London, 1969.

20. Lide D R, CRC. Handbook of Chemistry and Physics, $78^{\text {th }}$ Ed., CRC Press: Boca Raton, 1971.

21. Gupta K K, Bansal A K, Singh P J and Sharma K S, Indian J Phys., 2005, 79(2), 147-152.

22. Madhu Mohan T, Sastry S S and Murthy V R K, J Mol Struc., 2010, 973, 157-162.

23. Kumbharkhane A C, Puranik S M and Mehrotra S C, J Sol Chem., 1993, 22, 219-229.

24. Chaudhari A, Patil C S, Shankarwar A G, Arbad B R and Mehrotra S C, J Korean Chem Soc., 2001, 45(3), 201-206.

25. Kauzmann W, Rev Mod Phys., 1942, 14, 12-44.

26. Jianfeng Lou, Paravastu A K, Laibinis P E and Hatton T A, J Phys Chem A, 1997, 101, 9892-9899.

27. Madhu Mohan T, Sreehari Sastry S and Murthy V R K, Indian J Pure Appl Phys., 2010, 48, 668-675.

28. Chitra M, Subramanyam B and Murthy V R K, Mol Phys., 2001, 99(18), 1569-1573.

29. Satheesh V, Jayaraj M and Sobhanadri J, J Mol Liq., 1995, 64, 247-261. 
30. Parthipan G, Arivazhagan G and Thenappan T, Philosophical Magazine Letters, 2008, 88(2), 125-136.

31. Swain B B, Current Sci., 1985, 54, 504-506.

32. Rana V A, Vyas A D and Mehrotra S C, J Mol Liq., 2002, 102, 379-391.

33. Chaudhari A, Antia D, Raju G, Chaudhari H, Prakash K, Navinkumar N and Suresh M, Proc Natl Sci Counc Roc (a)., 2001, 25, 205-210.

34. Sengwa R J, Madhvi Sonu S and Shobha S, J Sol Chem., 2006, 35, 1037.

35. Rajala G E and Crossley J, Candadian J Chem., 1972, 50, 99-103.

36. Patil S P, Chaudari A S, Lokhande M P, Landle M K and Mehrotra S C, J Chem Eng Data, 1999, 44, 875-878.

37. Thenappan T and Prabakar Devaraj A, J Mol Liq., 2006, 123, 72-79.

38. Reed T M and Taylor T E, J Phys Chem., 1959, 63, 58-67.

39. Palani R, Geetha A, Saravanan S and Sunil D T, Rasayan J Chem., 2008, 1, 481-488

40. Boja B S, Siddiqi M A, Fornefeld S U and Svejda P, J Chem Engg Data, 2002, 47, 250-253. 